\title{
A Multi-Step Assessment Scheme for Seismic Network Site Selection in Densely Populated Areas
}

\author{
Katrin Plenkers • Stephan Husen • Toni Kraft
}

Received: 25 April 2014 / Accepted: 1 June 2015 /Published online: 12 June 2015

(C) Springer Science+Business Media Dordrecht 2015

\begin{abstract}
We developed a multi-step assessment scheme for improved site selection during seismic network installation in densely populated areas. Site selection is a complex process where different aspects (seismic background noise, geology, and financing) have to be taken into account. In order to improve this process, we developed a step-wise approach that allows quantifying the quality of a site by using, in addition to expert judgement and test measurements, two weighting functions as well as reference stations. Our approach ensures that the recording quality aimed for is reached and makes different sites quantitatively comparable to each other. Last but not least, it is an easy way to document the decision process, because all relevant parameters are listed, quantified, and weighted.

Our assessment scheme incorporates seven fundamental steps: First, potential sites are identified and pre-evaluated in the office (step 1). Second, potential sites are visited during a site survey (step 2) and then classified using the first weighting function (step 3 ) that
\end{abstract}

K. Plenkers $\cdot$ S. Husen $\cdot$ T. Kraft

ETH Zurich, Swiss Seismological Service, Sonneggstr. 5, 8092 Zurich, Switzerland

Present Address:

K. Plenkers $(\bowtie)$

Gesellschaft für Materialprüfung und Geophysik GMuG mbH, Dieselstr. 9, 61231 Bad Nauheim, Germany

e-mail: k.plenkers@gmug.eu

Present Address:

S. Husen

Gesundheitsdepartement Basel Stadt, Kannenfeldstrasse 2,

4012 Basel, Switzerland identifies those sites most suitable for test measurements (step 4). Test measurements are conducted and analyzed in order to quantify seismic background noise and site effects. The results of the analysis are evaluated using the second weighting function (step 6). Finally, the overall quality is assessed (step 7) by using reference stations and pre-defined quality benchmarks to insure that chosen sites are suitable for the designated monitoring purpose. We demonstrate the multi-step assessment scheme by applying it to a densification of an existing seismic network.

Keywords Seismic monitoring · Network design · Seismic noise $\cdot$ Microseismicity

\section{Introduction}

The need to monitor seismic events with small magnitudes $(M<2)$ in densely populated areas is growing. First, geotechnical operations (e.g., mining, geothermal power production, waste water disposal, or (un-)conventional gas exploration) are more often initiated near populated areas. Because many of these geotechnologies have the potential to induce seismicity, monitoring of small magnitude earthquakes is necessary for real-time risk assessment and the implementation of mitigation strategies. Second, delicate structures as, e.g., underground nuclear waste repositories or nuclear power plants require a longterm risk assessment. Here, the monitoring of small events will increase the number of events recorded and allow to monitor tectonic processes in high resolution. In 
this context, seismic monitoring is often a key parameter for geotechnical engineering, sophisticated research as well as for gaining public acceptance of critical projects in urban areas.

When a new seismic network or the densification of an existing one is planned, first-of-all, the target of the network must be defined, i.e., defining which seismic signals the network is aiming for. Only when the target is defined, the requirements to the network are clear and can be considered during the network design.

Furthermore, two additional, important aspects need to be considered early on: (i) network geometry and (ii) site selection. Only a careful assessment of all these aspects will ensure the recording of high-quality and most useful data. Whereas the topic of optimal network design is well covered in the existing literature (Kijko 1977; Souriau and Woodhouse 1985; Hardt and Scherbaum 1994; Zayats and Steinberg 2010; Kraft et al. 2013), the subsequent aspects are covered only rarely.

In this study, we focus on site selection only. This means, we assume that a decision on the network geometry as well as on the number of stations has been made (e.g., using optimal network design methods) and focus on what follows after, namely the process of finding suitable sites for station installation.

In seismic site selection different criteria need to be taken into account: the local background noise, the local geological setting, and the given technical infrastructure as well as legal or political aspects. Selecting appropriate station sites is essential, because local variations in geology and/or local background noise may alter data quality significantly. This becomes particularly important when monitoring small magnitude $(\mathrm{M}<2.0)$ events. Finding appropriate station sites is especially difficult in densely populated areas, including cities and their surroundings, because here a complex pattern of seismic background noise is displayed. The level of seismic background noise is in general very high and often of non-stationary character, due to traffic and other human activities. Furthermore, many noise sources are recorded over large distances up to several kilometers and recording quality depends in a complex manner on the underground geology.

Seismic site selection is normally based on expertjudgement and seismic background noise measurements. A detailed introduction to this topic is given by Trnkoczy et al. (2009). The decision is often successful, because experienced personnel are able to consider and weight the different aspects.
Nonetheless, site selection based on expertjudgement suffers from a lack of quantitative comparability between different site assessments and between assessments by different individuals. This makes the objective reevaluation whether the best site was found difficult. Furthermore, justifying the choice towards community decision-makers, funding agencies, or the public is difficult. The latter is especially important in projects where there is political interest to demonstrate that an appropriate monitoring of seismicity was established.

In this paper, we propose a multi-step assessment scheme that finds optimal station sites by formulating objective criteria and weighting functions. The goal of our approach is to optimize site selection and make it comparable. Moreover, we demonstrate that our approach allows easy documentation, which is not only beneficial for reporting but also for the future operation of the network.

After introducing our objective criteria and weighting functions, we apply our approach to a regional network in northern Switzerland that densifies an existing broadband network. We published some general aspects of our approach in a German guideline for microseismic monitoring (Baisch et al. 2012).

\section{Multi-Step Assessment Scheme}

Our multi-step assessment scheme starts after the general network geometry has been designed, e.g., by using network optimizations methods, and so-called site perimeters have been defined. By site perimeter, we mean the area around the optimal station location obtained in the network design process, wherein the final station may be located. Generally, multiple candidate locations will exist in one site perimeter. The multi-step assessment scheme allows to quantify and to qualify these proposed sites by combining and weighting general information on local geology, infrastructure, legal permission, and seismic background noise as derived from test measurements. Key elements are two weighting functions and the definition of reference stations. The weighting functions combine and weigh all aspects necessary for the decision making and identify the most suitable candidate for installation.

The assessment scheme we developed consists of seven steps (Fig. 1). In the first step, all potential sites within a site perimeter are identified and evaluated in a 
Input: $\quad$ Network Geometry (from Network Optimization Algorithm)

Multi-Step Assessment Scheme

\section{Step 1 Pre-Assessment} $\checkmark$ Potential Sites

Step 2 Site Survey $\downarrow$ Site Selection
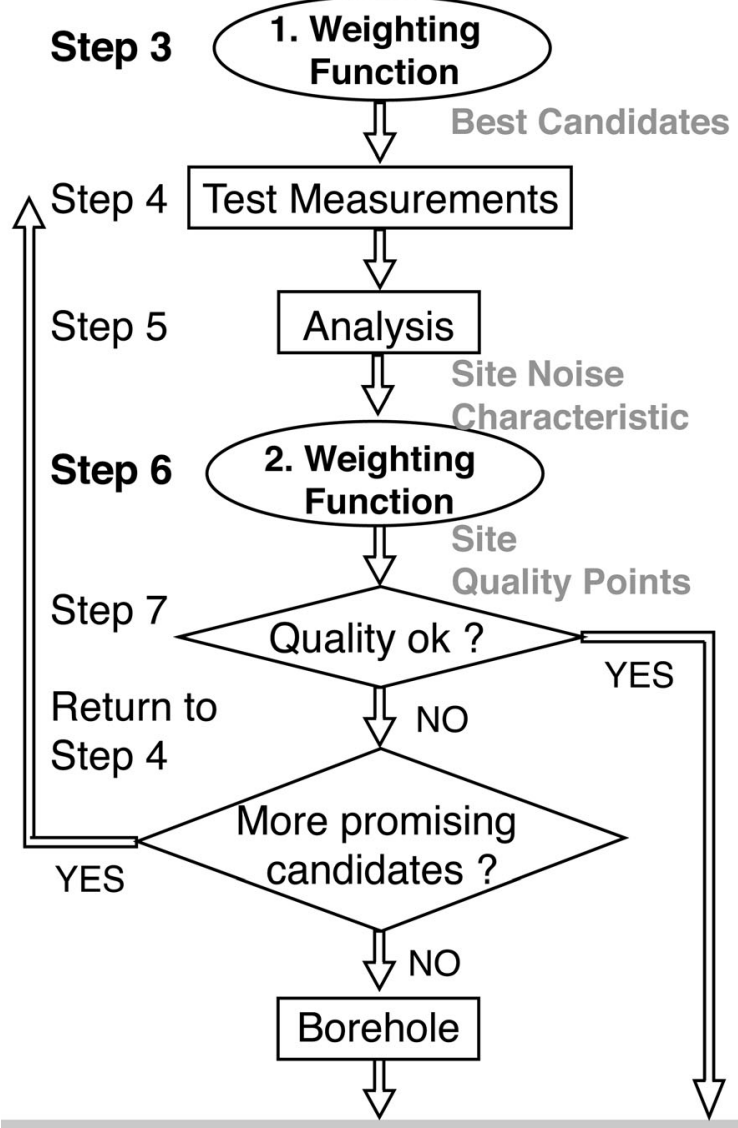

\section{Output: \\ Site Decision \& Station Installation}

Fig. 1 Multi-step assessment scheme. Process diagram illustrating the work-flow of the assessment scheme. Results of individual work steps are shown in grey to the right. Further discussion in text

desk-based investigation, considering topographic maps and GIS information. The most important parameters for site selection (expected seismic background noise, geology, and infrastructure) are taken into account. This pre-evaluation generates a list of potential sites. In the second step, all potential sites are visited by a trained seismologist or a seismological-trained technician for site survey. The site survey aims to increase the knowledge about the site, to exclude unfavorable sites, and to establish first contact to land owners. In the third step, we evaluate all site survey information for each potential site using a first weighting function and identify the most promising candidates for subsequent test measurements.

Test measurements are performed at the most promising sites (step 4) and analyzed (step 5). Results from the test measurements are finally combined and weighted (step 6) using a second weighting function that assigns quality points to all sites. If pre-defined quality criteria are met (step 7), the site selection is finished, and the seismic station can be built. If not, our assessment scheme returns to step 4, and more test measurements are conducted. Alternatively, other measures to improve site quality, such as borehole installations, are considered.

The proposed site selection approach has been used so far in the site selection process of several networks in Switzerland. In the following, we illustrate our approach at the example of the NAGRAnetwork that represents a densification of the existing Swiss Digital Seismic Network (SDSNet) in northern Switzerland. Under a contract given by National Cooperative for the Disposal of Radioactive Waste (NAGRA), ten new seismic stations were planned in order to improve location accuracy and to lower the magnitude of completeness (Mc; e.g., Mignan and Wössner 2012) of local seismicity in northern Switzerland (Fig. 2). The densification of the network is part of the ongoing search for radioactive waste repositories in the same region (for detailed information see www.nagra.ch).

The NAGRA-network aims for the monitoring of microseismicity $(\mathrm{M}<2)$ in a densely populated region with poor geology (Swiss Molasse basin) within site perimeters with a $10-\mathrm{km}$ radius. These challenging boundary conditions required a sophisticated site selection scheme that combines and weights all available information.

The geometry of the NAGRA-network was defined using a network optimization approach developed by Kraft et al. (2013), which specifically addresses the problem of optimal network design in densely populated areas. Their simulated annealing approach is able to take into account local noise conditions as derived from available information on land-use. 


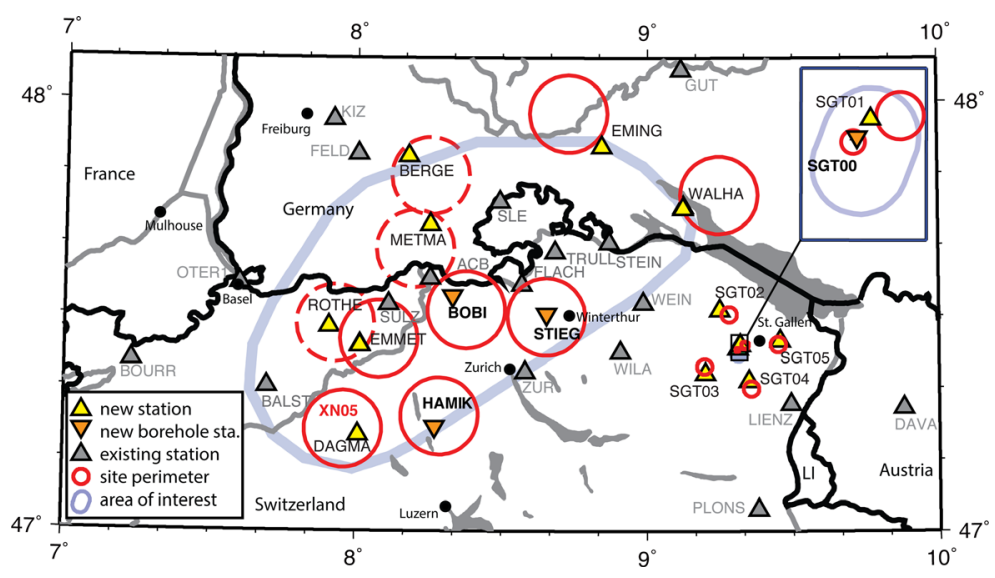

Fig. 2 Map showing the regional NAGRA-network in the SwissGerman border region 1. Site selection was performed using the multi-step assessment scheme. The network aims to improve the monitoring of microseismicity in the area of interest, shown as grey shades. Site perimeters are shown as red circles (solid line; geology is dominated by molasse rock; dashed line geology is

\subsection{Step 1: Site Pre-Evaluation}

In the first step, a preliminary desk-based site evaluation is performed studying topographic and geological maps, as well as by gathering additional information from the internet. The goal is to identify all potential sites within a site perimeter for a subsequent site survey. Potential sites correspond to sites that promise low and stationary background noise, hard-rock geology (if possible) and (if necessary) existing infrastructure such as electricity and access to data-communication. A comprehensive introduction to site selection was given by Trnkoczy et al. (2009).

In order to evaluate the expected background noise, the pre-evaluation aims to identify and to roughly quantify noise sources. Often sites can already be excluded from further consideration during pre-evaluation in case dominant noise sources (e.g., train lines, highways, industry, urban settlements, and electrical devices) exist at relevant distances. What is considered a dominant noise sources dependents on the frequency range of the seismic signals aimed to be monitored. In our study, we require in general a minimum distance of about $1 \mathrm{~km}$ from settlements to avoid diurnal noise and a minimum distance to train lines and highways of 3 to $5 \mathrm{~km}$. In our experience, the distances given by Trnkoczy et al. (2009) are not applicable, because of the high numbers of different noise sources that are found in densely populated areas. The effect of the local geology has to be considered in the site selection process early on, dominated by competent crystalline or mesozoic rocks). Existing stations of the SDSnet are shown as grey triangles. New stations realized after applying the site multi-step assessment scheme are shown as yellow (surface station) and orange (borehole station) triangles

because it can significantly alter the incoming wave field both in amplitude and duration (e.g., Bard et al. 1988; Aki 1993). As a role of thumb crystalline basement is therefore preferable over sedimentary rocks over unconsolidated sediments (Trnkoczy et al. 2009). During site pre-evaluation, we study geological maps to decide whether a site might be suitable or whether strong site effects are to be expected. To gather information about the local infrastructure (electricity and telephone) during site pre-evaluation is often difficult. Maps provided by electricity or telephone companies can be useful to identify access points.

\subsection{Step 2: Site Survey}

During step 2, all potential sites identified in step 1 are visited by an experienced seismologist or a seismologically-trained technician. Along with carrying out a visual inspection of the site, the site survey focuses on three aspects: (i) Verify information collected in step 1 and gather more detailed information, (ii) identify local noise sources, and (iii) establish first contact to the land owners.

One focus is the gathering of information regarding the infrastructure: Is electricity and telephone available at the site? Are buildings suitable for seismic station installation or is the installation in a newly build vault possible? Does the vegetation allow for sufficient GPScoverage? The availability of infrastructure has a direct impact on the financial costs necessary to build the 
station. Furthermore, the impact of local noise sources, such as cattle, machines, and people, cannot be evaluated in step 1 and has to be investigated during site survey.

We emphasize the importance to contact land owners of potential sites during site survey for several reasons. First, it is often very difficult to get contact information from the office, especially in countries where this information is restricted. To gather as many contacts as possible in the field is therefore efficient. Second, detailed information about potential sites are often revealed, when talking to a local person. Are there any hidden machines? How is the site used and how will it be used in future? Are changes in land ownership to be expected? This additional information can have a crucial influence on the site decision, especially in case a long term deployment is planned. Moreover, the site survey allows explaining the project to people in person. Especially, in those cases, where people might be worried about the impact of the installation, personal communication is normally much easier than via mail or telephone. Informing people early on increases the probability to get the permission for installation later on. For these reasons, project descriptions together with the contacts of the responsible seismologist were distributed in the NAGRA-project.
Last, but not least, the site survey is used to exclude sites that obviously are not able to meet the quality criteria, i.e., sites where dominant noise sources are present or sites situated in worst geological settings.

\subsection{Step 3: Site Evaluation with Weighting Function 1}

The goal of step 3 is to combine and weight all information gathered during step 1 and step 2. To do so, we define the following weighting function:

$\mathrm{P} 1=(\mathrm{u} 1 * \mathrm{~N} 1+\mathrm{u} 2 * \mathrm{G}+\mathrm{u} 3 * \mathrm{I}) * \mathrm{D}$

with the quality criteria N1 for expected seismic background noise, $\mathrm{G}$ for local geology, I for local infrastructure (electricity and telephone), and D for the distance to the optimal design location in the site perimeter. The equation yields priority points $\mathrm{P} 1$, which are directly linked to the expected quality of the site. The idea of this weighting function is to assign simple quality values (1, good; 0.5 , acceptable; 0 , poor) to each quality criteria (N, $\mathrm{G}$, I, and D). Table 1 shows how quality values have been defined for each of the quality criteria for the NAGRANetwork. The term "expected seismic background noise" refers to the fact that at this step seismic noise is not
Table 1 Definition of quality values for the first weighting function (Eq. 1)

\begin{tabular}{lll}
\hline Quality criteria & Quality value & Description \\
\hline Expected noise N & 1 & Low background noise expected \\
& 0.5 & a) Site occasionally affected by higher noise \\
& b) Effect of identified noise source unclear \\
Site excluded & High background noise expected \\
& 1 & JBF: Crystalline Basement; MOL: competent Molasse \\
& 0.5 & a) Geology not reliable known \\
& Site excluded & b) JBF: Molasse; MOL: Moraine \\
& 1 & Brash, rubble, peat (JBF: Moraine) \\
Electricity E & 0.5 & a) Electricity available in a bit larger distance \\
& & b) Availability of electricity unknown \\
& 0 & No electricity available \\
Communication C & 1 & a) Land line with sufficient bandwidth available \\
& 0.5 & a) Availability unknown \\
& 0.5 & b) No land line but UMTS available \\
& 0 & Neither land line nor UMTS available \\
& 1 & Site situated in 5-km radius \\
Distance D & Site situated in 10-km radius \\
& & Site situated just outside site perimeter \\
& &
\end{tabular}


measured but estimated from the information gathered in step 1 and step 2 based on seismological experience.

The relative importance of the quality criteria is strongly project depended and can be controlled by the weighting factors ( $\mathrm{u} 1, \mathrm{u} 2$, and $\mathrm{u} 3$ ). For microseismic monitoring in urban areas, we recommend a weighting scheme that follows:

u1 $>=\mathrm{u} 2>=\mathrm{u} 3$

In the site selection process of the NAGRA-network, we used the following weighting factors: $\mathrm{u} 1=\mathrm{u} 2=4$ and $\mathrm{u} 3=2$.

Our choice followed the logic that in densely populated areas with mostly poor geology sites with low background noise and better geology are more important than existing infrastructure for monitoring microseismicity $(\mathrm{M}<2)$.

The local geology criteria $\mathrm{G}$ is evaluated based on the surface geology as given by geological maps. Nearsurface geology is, among background noise, of primary importance when selecting potential sites, but it is necessary to evaluate local geology in the context of the regional tectonic setting, i.e., it normally does not make sense to look for crystalline rocks in a Molasse basin. We therefore allocate each site perimeter to a regional geological unit and assign quality values accordingly. In perimeters where hard rock sites are existing, a lower quality value is given to sites on sedimentary rocks, e.g., of the Marine Molasse. In geological units, on the other hand, where no crystalline basement sites are existing, sedimentary rock gets the highest quality value. As an example, three site perimeters of the NAGRA-network (Fig. 2) are located in the Jura Mountains, the Svabian Alp or in the Black Forest (JBF) where crystalline basement and competent sedimentary rocks (e.g. limestones) are outcropping. All other perimeters are dominated by more incompetent sedimentary rocks of the forealpin Molasse Basin (MOL). The resulting quality values are listed in Table 1 .

The need to use existing infrastructure depends on the financial budget, the duration of the planned installation, climate conditions as well as social aspects (risk for vandalism, acceptance, etc.). We consider the infrastructure criteria (I) to be mainly depended on the availability of mains power (E) and data communication (C) and combine them in an additional weighting function:

$\mathrm{I}=\mathrm{v} 1 * \mathrm{E}+\mathrm{v} 2 * \mathrm{C}$

where the weighting factors $\mathrm{v} 1$ and $\mathrm{v} 2$ again control the relative project dependent importance of the quality criteria $\mathrm{E}$ and $\mathrm{C}$. In the NAGRA-project, we used the following weighting factors: $\mathrm{v} 1=1$ and $\mathrm{v} 2=0.5$.

In terms of data communication, telephone lines were preferred over mobile networks for the NAGRAnetwork because coverage of mobile antennas was sparse in many site perimeters. A sparse coverage often results in unstable data transmission. For this reason, smaller quality values were assigned for mobile communication in Equation 3 (Table 1).

After all factors are considered, Equation 1 allows to compare and prioritize all potential sites in a site perimeter. Sites with the highest priority points $\mathrm{P} 1$ as given by Equation 1 identify the most promising candidates that are chosen in the following for test measurements.

\subsection{Step 4: Test Measurement}

In step 4, test measurements are conducted at those sites with the highest priority points (P1). The goals of the test measurements are to analyze the actual local background noise and to evaluate a first-order site response. The duration of each test measurement depends on the boundary conditions of the project.

The NAGRA-networks aim at recording local seismicity with dominant frequencies larger than $1 \mathrm{~Hz}$. We, therefore, chose to conduct test measurements with a minimum duration of 1 week as high frequency ( $\mathrm{f}>$ $1 \mathrm{~Hz}$ ) seismic noise is often dominated by daily or weekly variation patterns. Some noise sources are active only on workdays, whereas others become apparent on non-working days only. In addition, strong noise sources such as machinery used, e.g., in farms, water reservoirs, or sewers are often not in use on a daily basis. A 1-week-long test measurement is normally able to record the most typical noise sources affecting the tested site. We point out that long-term fluctuations in seismic background noise are obviously not captured during a 1week test measurement. This might be especially crucial for sites that undergo strong seasonal fluctuations in human activity such as touristic areas. In the NAGRAnetwork, the influence of seasonal noise variations was evaluated by expert judgement during site survey (step 2) only.

During test measurements, seismometers are deployed at exactly the site intended for final installation. For example, sensors are employed in existing structures, when the final installation was planned in an existing structure. They are employed in the free field using an insulation box for shielding, in those cases 
where the construction of a new concrete foundation and vault was planned. Also, the same sensors as intended for the final installation are used for the measurements.

For a meaningful analysis, it is important to gather as much information on the site conditions during the measurement as possible: Is the background noise that is recorded typical for the site? Are there any negative (e.g., temporary construction, temporary work processes such as grass cutting or timbering, and bad weather) or positive (near-by road closed and inhabitants on vacation) factors that alter the result and are not representative for the site? For obvious reasons, these boundary conditions need to be considered during the analysis of the seismic background noise.

\subsection{Step 5: Data Analysis}

Test measurements are analyzed in step 5 considering the following aspects:

- Mean noise amplitudes (NA)

- Occurrence and amplitude of narrow frequency noise (NM),

- Occurrence and amplitude of transient signals and diurnal variations (NT),

- Quality of local earthquake phase onsets (if available, O).

The frequency range analyzed using the test measurement data must correspond to the expected frequency range of seismic signals aimed for by the considered project. Because the NAGRA network targets local seismicity recorded at distances $<100 \mathrm{~km}, \mathrm{NA}$ and $\mathrm{NM}$ are analyzed in the frequency ranges 1 and $40 \mathrm{~Hz}$.

Mean noise amplitudes are analyzed using the software PQLX (Mc Namara and Boaz 2011) following the approach used by Kraft et al. (2013). We computed probability density functions of the power spectral density (PSDPDF) for the ground acceleration recorded during the test measurements. We derived the mean function of the PSDPDF for each test site. The mean function represents the mean noise level observed at the corresponding test site for the analyzed time window of approximately 1 week. Narrow frequency noises are a major noise source, because they degrade the waveform quality permanently. In case the frequency content corresponds to the dominant frequency content of the seismic signal, they can increase the uncertainty in picking earthquake onsets significantly. Often narrow frequency noise is generated by machineries (e.g., turbines and generators). Due to the averaging of the PDF over one octave bandwidth in PQLX, it is hard to identify narrow frequency noise using PSDPDF. Therefore, we study the occurrence and amplitude of narrow frequency noise using 24-h spectrograms (Groos and Ritter 2009).

Transient noise signals can affect seismic event triggering and signal recording significantly if their amplitude, duration, and frequency content are comparable to the earthquake signal as described by Plenkers et al. (2013) and Fischer and Bachura (2014). The nature of transient noise events is therefore also studied using the 24-h spectrograms, as well as by waveform analysis. We visually inspect the amplitude, the duration, the shape, and the recurrence time of transient signals. Some typical transient event waveforms are shown in Ritter and Sudhaus (2007). The information about potential local noise sources that have been gathered in working step 1 , step 2 , and step 4 is crucial to understand the origin of the observed transient noise events.

Since local site conditions can significantly alter the incoming earthquake signal, we analyze in addition seismic phase onsets of recorded local events. This analysis is of course only possible, in case local events were recorded during the test measurement period. We describe the procedure in more detail in the next section (step 6)

\subsection{Step 6: Weighting Function 2}

In step 6, results from the test measurement analysis (step 5) among other information, including installation costs and maintenance efforts, are combined and weighted using a second weighting function:

$\mathrm{P} 2=(\mathrm{w} 1 * \mathrm{~N} 2+\mathrm{w} 2 * \mathrm{O}+\mathrm{w} 3 * \mathrm{~F}+\mathrm{w} 4 * \mathrm{M}+\mathrm{w} 5 * \mathrm{D}) * \mathrm{~A}$

$\mathrm{P} 2$ is the final quality of the site that is defined by the following quality criteria: N2 for the quality of the measured local background noise, $\mathrm{O}$ represents information about the pick quality of earthquake phase arrival times, F represents the installation costs to build the station, $\mathrm{M}$ weights the maintenance costs, and $\mathrm{D}$ is the distance to the optimal design location in the site perimeter (same as in Eq. 1). The criteria are weighted using weighting factors $w 1$ to w5. As in Eq. 1, the weighting factors are strongly project dependent and have to be 
chosen based on the monitoring requirements of the network under investigation.

The last parameter A represents the status of legal permission. It can have values of 1 (permission by the land owner is available) or 0 (no permission). The constant A was implemented in Eq. 6, because legal permission may take long and the site evaluation process should not be delayed. The constant A therefore documents the case where a good site was found but was later excluded purely owing to the failure of gaining legal permission.

The quality criteria N2 for background noise are composed of the above mentioned three quality criteria: mean background noise amplitude (NA), narrow frequency noise (NM), and transient noise events (NT). As discussed in the previous section, they are derived from the test measurement analysis. Hence, N2 can be evaluated as:

$\mathrm{N} 2=(\times 1 * \mathrm{NA}+\times 2 * \mathrm{NM} * \times 3 * \mathrm{NT}) /(\times 1+\times 2+\times 3)$

where $\times 1, \times 2$, and $\times 3$ are weighting factors. We use $\times 1=2$ and $\times 2=\times 3=1$ for the NAGRA-network. We give double weight to NA, because low mean background noise amplitude was explicitly assumed beforehand in the network optimization (Kraft et al. 2013). We analyze NA and NM in two frequency bands, namely between 1 and $10 \mathrm{~Hz}$ (NA1 and NM1) as well as between 10 and $40 \mathrm{~Hz}$ (NA2 and NM2). We give double weight to the frequency band $1-10 \mathrm{~Hz}$ as we consider this the dominant frequency band for the monitoring target of the NAGRA-network:

$$
\begin{aligned}
& \mathrm{NA}=(2 * \mathrm{NA} 1+\mathrm{NA} 2) /(3) \\
& \mathrm{NM}=(2 * \mathrm{NM} 1+\mathrm{NM} 2) /(3)
\end{aligned}
$$

Quality values for the quality criteria in Eqs. 5 and 6 are summarized in Table 2. NA are compared to those of selected reference stations. Our reference station A describes the noise level we are aiming for. Reference station B describes the maximum acceptable noise level. We aim to define goals that are not only good from a theoretical point of view but that may be realistically reached in the area of interest. In our example of the densification of an existing network, we use existing stations in the wider region of interest to determine the two reference stations. If no stations exist in this area, stations installed elsewhere, but in a similar setting may be used to define the reference stations. We do not choose the best station in the area (lowest background noise) for reference station A, because we cannot expect, in a carefully designed national network like the SDSnet, that sites better than the best station are likely to be found. To account for possible varying site amplification characteristics, different reference stations should be selected for different geologic units. For the NAGR A-project, we chose one set of reference stations for the Jura and Black Forest (JBF) units and a different set for the Molasse (MOL) unit (Table 3).

Beside background noise, we also analyze the phase onset of weak local earthquakes recorded during the test measurements. We do this to gain additional
Table 2 Definition of quality values for the measured back-

\begin{tabular}{|c|c|c|}
\hline Quality criteria & Quality value & Description \\
\hline \multirow[t]{4}{*}{ NA } & 1 & Amplitude $<$ Amplitude reference station A \\
\hline & 0.5 & Amplitude $>$ amplitude reference station A and \\
\hline & & Amplitude $<$ amplitude reference station B \\
\hline & 0 & Amplitude $>$ amplitude reference station B \\
\hline \multirow[t]{4}{*}{ NM } & 1 & No narrow frequency noise with amplitude $>30 \mathrm{~nm} / \mathrm{s}$ \\
\hline & 0.5 & narrow frequency noise with low amplitude $<120 \mathrm{~nm} / \mathrm{s}$ \\
\hline & 0 & a) strong narrow frequency noise (amp. $>120 \mathrm{~nm} / \mathrm{s}$ ) \\
\hline & & b) several narrow frequency noises (amp. $>30 \mathrm{~nm} / \mathrm{s}$ ) \\
\hline \multirow[t]{5}{*}{ NT } & 1 & Only rare transient noise signals \\
\hline & 0.5 & a) clear diurnal variations (amplitude $<120 \mathrm{~nm} / \mathrm{s}$ ) \\
\hline & & b) regular transient noise signals (amp. $>30 \mathrm{~nm} / \mathrm{s}$ ) \\
\hline & 0 & a) strong diurnal variations (amp. $>120 \mathrm{~nm} / \mathrm{s}$ ) \\
\hline & & b) regular transient noise signals (amp. $>120 \mathrm{~nm} / \mathrm{s}$ ) \\
\hline
\end{tabular}
ground noise criteria N2 (Eq. 4) 
Table 3 Reference stations used in site evaluation of the NAGRA network

\begin{tabular}{lllll}
\hline Station & Reference & Geology & $\mathrm{V}_{\mathrm{rms}}(1-10 \mathrm{~Hz})$ & $\mathrm{V}_{\mathrm{rms}}(10-40 \mathrm{~Hz})$ \\
\hline BALST & A & Malm & $9.97 \mathrm{~nm} / \mathrm{s}$ & $12.19 \mathrm{~nm} / \mathrm{s}$ \\
TORNY & B & $\begin{array}{c}\text { Moraine (overlying Upper } \\
\text { Marine Molasse) }\end{array}$ & $18.82 \mathrm{~nm} / \mathrm{s}$ & $28.71 \mathrm{~nm} / \mathrm{s}$ \\
SULZ & A & Dogger & $19.64 \mathrm{~nm} / \mathrm{s}$ & $21.38 \mathrm{~nm} / \mathrm{s}$ \\
FLACH & B & Aquitanien (Lower & $35.07 \mathrm{~nm} / \mathrm{s}$ & $45.26 \mathrm{~nm} / \mathrm{s}$ \\
& & Freshwater Molasse) & \\
\hline
\end{tabular}

information on local site effects and how they alter the incoming seismic signal.

In order to evaluate the quality of the phase onset $(O)$ of weak local earthquakes at a station, we consider two pick quality criteria, one for the observed pick quality $\left(O_{\mathrm{B}}\right)$, and a second for the theoretically expected pick quality $\left(O_{\mathrm{E}}\right)$ in the following way:

$$
O=c * O_{\mathrm{B}} / O_{\mathrm{E}}+(1-\mathrm{c}) * G
$$

$G$ is the geology quality criteria defined in step 3 (Table 1), and the parameter $c$ controls whether an earthquake was recorded during the test measurements (1) or not (0). The quality values for $O_{\mathrm{B}}$ and $O_{\mathrm{E}}$ are summarized in Table 4.

Observed pick quality $O_{\mathrm{B}}$ is based on the pick uncertainty of the first-arriving P-wave. In our study, we follow the routine picking procedure as implemented at the Swiss Seismological Service (Diehl et al. 2009), which defines specific guidelines for choosing appropriate picking uncertainties.

In our study, we derive the expected pick quality $O_{\mathrm{E}}$ from pick probability distributions $P_{\mathrm{D}}$, as developed in the probabilistic magnitude of completeness approach of Schorlemmer and Woessner (2008). Pick probability distributions describe the probability whether a certain event with a certain magnitude in a certain distance is picked or not,

Table 4 Definition of Quality values for the observed and expected pick quality criteria (Eq. 7)

\begin{tabular}{lll}
\hline Parameter & $\begin{array}{l}\text { Quality } \\
\text { factor }\end{array}$ & Description \\
\hline Observed pick quality $O_{\mathrm{B}}$ & 1 & Pick uncertainty $\pm 0.05 \mathrm{~s}$ \\
& 0.5 & Pick uncertainty $\pm 0.1 \mathrm{~s}$ \\
& 0 & Pick uncertainty $> \pm 0.2 \mathrm{~s}$ \\
Expected pick quality $O_{\mathrm{E}}$ & 1 & $P_{\mathrm{D}}>80 \%$ \\
& 0.5 & $P_{\mathrm{D}}>60 \%$ \\
& 0.01 & $P_{\mathrm{D}}<60 \%$ \\
\hline
\end{tabular}

based on the analysis of a seismic catalog. In our study, we use pick probability distributions $P_{\mathrm{D}}$ from the same reference stations used in the analysis of the background noise. As an example, the pick probability distribution of reference station FLACH is given in Fig. 3. We extract the expected pick quality $O_{\mathrm{E}}$ from the pick probability by assuming that a high pick probability coincides with a good pick quality, as described, e.g., by Aki and Lee (1976). This assumption is justified for our study as our network is aiming for tectonic earthquakes of small to moderate magnitudes, which are often characterized by rather impulsive onsets.

In Eq. 7, observed pick quality $O_{\mathrm{B}}$ is normalized by expected pick quality $O_{\mathrm{E}}$ to account for the dependence of the pick quality on the signal-to-noise ratio and for the short test measurement periods. In our study, observed pick quality $O_{\mathrm{B}}$ will often be poor because seismicity in the study area is characterized by small magnitude events. Without normalization, this would always yield a poor quality factor $O$.

The quality criteria $\mathrm{F}$ in Eq. 4 evaluate whether financial costs to build the final station are within the financial budget of the project. Quality values for F are summarized in Table 5. The financial costs are the summary of all costs in the context of installing and building the final station. These include the costs for necessary construction work (e.g., building a new vault) as well as for installing power and communication lines at the station site. The costs acceptable for the station installation depend clearly on the financial budget of the project. Most often longterm installations (like the NAGRA-network) have a higher financial budget than temporary installations.

The quality criterion $\mathrm{M}$ evaluates how difficult the maintenance of the station at the candidate site will be. Quality factors for $\mathrm{M}$ are summarized in Table 5. A station is easy to maintain $(M=1)$ if the site is easily accessible all year round. Sites that need special permits or that are only accessible in certain times of the year are less favorable $(\mathrm{M}=0.5)$. Sites that are very difficult to access (e.g., only by helicopter or long travel) should be avoided $(\mathrm{M}=0)$. 

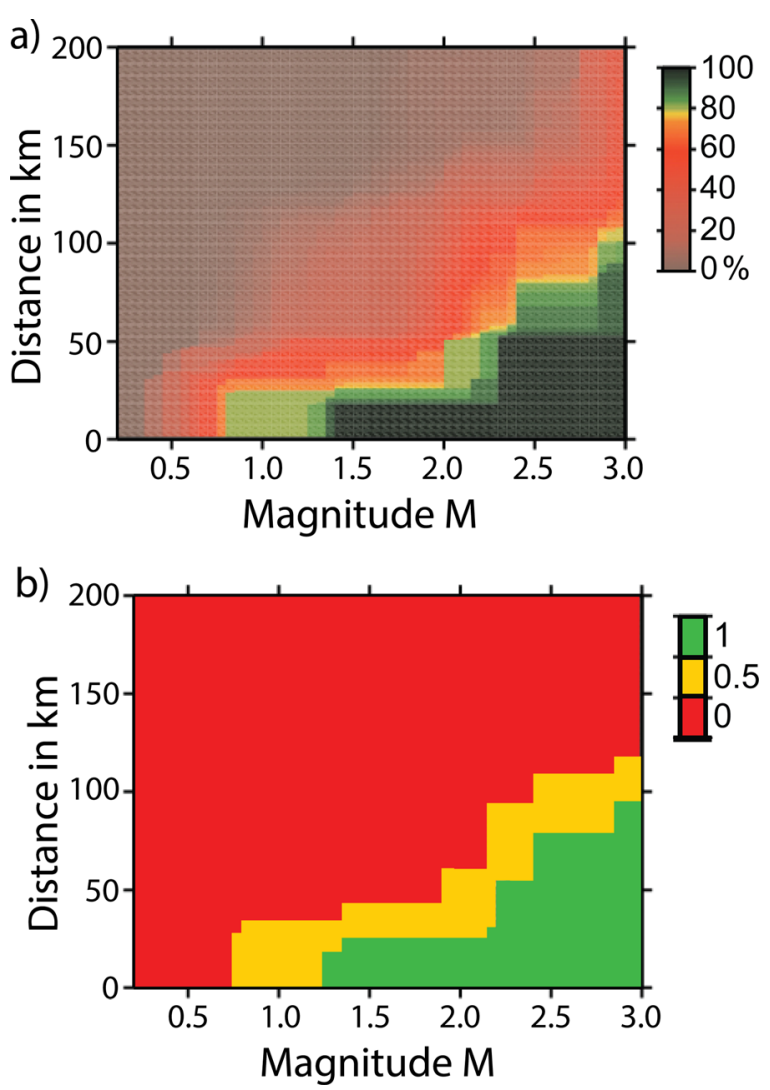

Fig. 3 Theoretical onset quality. a shows the pick probability distribution P_D of reference station FLACH as defined by Schorlemmer and Woessner (2008) and Nanjo et al. (2010). The pick probability distribution is calculated from pick information of seismic catalogs. In our study, we use the pick probability distributions of reference stations to define theoretical onset quality factors, as shown in (b). We hereby assume that a high pick probability corresponds to a good quality in onset pick (as shown, e.g., in Aki and Lee 1976) using the relation shown in Table 4

The weighting factors $\mathrm{w} 1, \mathrm{w} 2, \mathrm{w} 3, \mathrm{w} 4$, and $\mathrm{w} 5$ control the project-specific relative importance of the

Table 5 Definition of quality values for the quality criteria $\mathrm{F}$ (finances) and M (maintenance) (Eq. 4)

\begin{tabular}{lll}
\hline Parameter & $\begin{array}{l}\text { Quality } \\
\text { factor }\end{array}$ & Description \\
\hline Finances F & 1 & $\begin{array}{l}\text { Cost within financial budget } \\
\text { Costs tolerable } \\
\text { Cost above financial budget } \\
\end{array}$ \\
0.5 & 0 & $\begin{array}{l}\text { Site accessible } \\
\text { a) Site not accessible several weeks/year } \\
\text { b) Site accessible with special permit only }\end{array}$ \\
& 0.5 & Area not accessible by car
\end{tabular}

quality criteria in Eq. 6. They must be adjusted for each network individually accounting the boundary conditions of the project (desired background noise level, financial budget, flexibility in network geometry, etc.). For microseismic monitoring in urban areas, we recommend to set

$\mathrm{w} 1>=\mathrm{w} 2>=\mathrm{w} 3>=\mathrm{w} 4>=\mathrm{w} 5$

because, similar to Eq. 3, it is preferential to weight the data quality highest, in order to allow for monitoring of microseismicity with good signal-to-noise ratios. In case of high noise or strong site effects, the recording of microseismicity is prevented and the aim of the network cannot be fulfilled. In our study, we chose the following weighing factors for the NAGRA network: w1 = $\mathrm{w} 2=4$, w3 $=\mathrm{w} 4=2$ and $\mathrm{w} 5=1$.

For the NAGRA network, the quality of the local background noise N2 is weighted equally high as the quality of earthquake onset $O$, as both parameters give valuable information on data quality. Because the NAGRA network is planned to record seismicity for more than one decade, we weight the data quality higher than building and maintenance costs.

As a final outcome of step 6 (i.e., Eq. 6), each site is evaluated by a total number of quality points $\mathrm{P} 2$. This allows objectively classifying and ranking all sites according to all available information.

\subsection{Step 7: Final Quality Screening}

In step 7, we evaluate whether the candidate site found is suitable for the purpose of the monitoring network. In case a candidate site with high enough quality was found, the site for installing the seismic station is defined. In case that no appropriate site was identified, additional measures have to be taken into account.

The quality points $\mathrm{P} 2$ as computed in step 6 allow a comprehensive analysis of all available information. In this context, not only the total number of points but also individual quality factors should be considered. This should be done in the form of tables that list individual quality factors as well as total number of quality points. In order to ensure that only sites with a minimum quality are selected, we further introduce quality thresholds for $\mathrm{P} 2$ and $\mathrm{N} 2$.

For the NAGRA network, we define the following quality thresholds: The quality points $\mathrm{P} 2$ must reach a total number of $P 2 \geq 10$. In addition, the quality factor of 
the background noise N2 must reach a total number of $\mathrm{N} 2 \geq 0.6$. If these thresholds are reached, we assume that the quality of a candidate site is sufficient and allows for monitoring of microseismicity.

If a site is identified that fulfills the quality thresholds, the final candidate site is defined. Before installing the seismic station, one last data analysis is performed. Because the stations in the NAGRA network are meant for long-term monitoring, we analyze the first-order site effect of final candidate sites. This ensures that no sites are chosen that show strong site effects. We perform this analysis last, because it is more time consuming than the other analyses performed in step 5 . We analyze the site effects for the final candidate site only.

In order to assess the site effects, we compute horizontal to vertical (H/V) Fourier spectral ratios of ambient vibration recordings. This simple single station method allows a fast and sufficiently precise estimation of the presence (and the entity) of major seismic interfaces at depth (Nogoshi and Igarashi 1971; Nakamura 1989; Bard 1999). This is achieved by analyzing the variability of the H/V spectral amplitude over the different frequency bands. The most valuable information is the identification of the SH-wave fundamental frequency of resonance (f0) at the site. In addition, more sophisticated single station approaches are applied, namely the directional $\mathrm{H} / \mathrm{V}$ and polarization analysis (Burjànek et al. 2010), which are useful to assess the anisotropy of the wave field or the wavelet timefrequency decomposition.

Results from the $\mathrm{H} / \mathrm{V}$ and polarization analysis are discussed to evaluate the quality of the site. As a general rule, sites which exhibit a large amplitude peak in the $\mathrm{H} /$ $\mathrm{V}$ function are rejected, as this is a clear indication of the presence of a resonant low velocity layer. Also, very irregular $\mathrm{H} / \mathrm{V}$ functions with large variability over time (large standard deviation) are carefully considered case by case, as this could be an indication of bad soil conditions. Polarization is then used to discriminate the influence of the local topography or to identify other secondary phenomena like slope instability.

If no site fulfills the required quality criteria or in case the final candidate site exhibits a critical site effect, other measures have to be considered. For example, sites evaluated in step 3 that were not chosen for test measurements so far can be reevaluated. Especially, we recommend checking whether the results of the performed test measurements give new information about the overall noise field, which might alter the quality factor for the expected seismic background noise N1. In addition, it is also important to check whether sites with $\mathrm{N} 1=\mathrm{G}=1$ have been down-weighted in step 3 because they are located just outside the search perimeter $(\mathrm{D}<=0.5)$. In such cases, additional test measurements are a promising approach to proceed and to find a site that fulfills the quality thresholds.

If no additional sites with acceptable seismic background noise were found, borehole installations can be considered. Installations in shallow boreholes (100 to $200 \mathrm{~m}$ deep) are able to reduce the seismic background noise especially at frequencies $\mathrm{f}>5 \mathrm{~Hz}$ (Carter et al. 1991; Young et al. 1994, 1996). For this reason, borehole installations are often able to reduce local noises significantly. In addition, borehole installations are sometimes useful to reach more competent geology, which can also improve the signal quality.

Finally, in case that sites with acceptable seismic background noise are found but existing infrastructure is poor, alternative ways of providing power, such as fuel cells, or data communication, such as radio or satellite links, should be considered.

In summary, the decision which site to choose for installation still depends on expert judgment and existing boundary conditions. Nevertheless, our proposed multi-step assessment scheme allows to combine and to weight all necessary information in a transparent and informative way. This is a necessary requirement for a thoughtful and meaningful decision.

\section{Data Example}

To illustrate our multi-step assessment scheme, we present the full evaluation process for one example taken from the Nagra network. Site perimeter XN05 is located in the southern part of the Nagra network (Fig. 2). Geology is dominated by sediments (marls and sandstones) of the Swiss Molasse Basin. The $10 \mathrm{~km}$-search radius is located around the village of Reiden (Canton Luzern), south of the city of Olten (Fig. 4). Large parts of the landscape are dominated by agriculture and forests. Although this perimeter by first sight seems rural, the region is highly affected by cultural noise. Major motorways (A1 and A2) and railway lines for passenger and freight trains cut through the center and the northern part of the perimeter. Among these major traffic routes, medium-size villages (Oftringen, Zofingen, Reiden, 


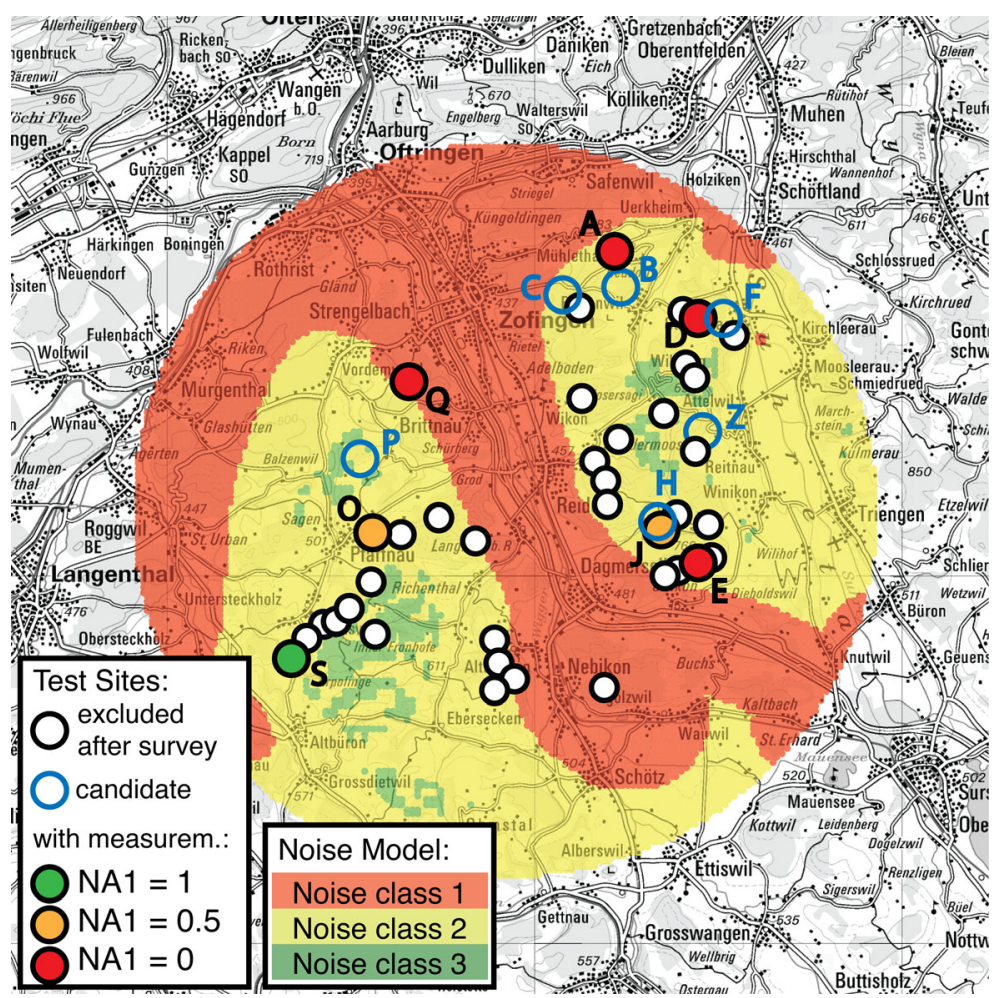

Fig. 4 Map showing search perimeter XN05 of Nagra network. Both the background noise model as used in the network optimization (Kraft et al. 2013), as well as the results of the site search are presented. Noise classes correspond to the following mean background noise velocities $\mathrm{v}$ : Noise class 1 (green) $\mathrm{v}<30 \mathrm{~nm} / \mathrm{s}$; noise class 2 (yellow) $30 \mathrm{~nm} / \mathrm{s}<\mathrm{v}<120 \mathrm{~nm} / \mathrm{s}$; noise class 3 (red) $\mathrm{v}>$ $120 \mathrm{~nm} / \mathrm{s}$. All candidate sites evaluated during the site selection process are shown by circles. White solid circles identify sites that

Dagmarsellen) locate in the center of the perimeter with small- to medium-sized industry areas (Fig. 4).

Because noise of these sources can reach for several kilometers, the first-order noise model (Kraft et al. 2013) predicts only a few sites with background noise amplitudes below $30 \mathrm{~nm} / \mathrm{s}$ (Fig. 4). This information was taken into account during site pre-evaluation (step 1) using topographic and geological maps. In total, more than 50 potential sites were identified; after site survey (step 2), 13 sites remained which were evaluated using the first weighting function (step 3). Sites that were excluded during the site survey showed strong local noise sources, the complete absence of electricity/ communication or access to the site was denied. Results of the first weighting function are summarized in Table 6. Based on these results, four sites (XN05J, $\mathrm{XN} 05 \mathrm{~S}, \mathrm{XN05Q}$, and XN05O) were chosen for test measurements. Although sites XN05P and XN05H were excluded after the site survey (step 2); blue circles identify sites with low quality points in step 3 . All other circles identify sites where test measurements were done. The color represents the quality criteria NA1 (measured mean noise amplitude), as defined in Table 2. (Source of Map in Background: Bundesamt für Landestopografie swisstopo, Landeskarte 1:500,000, www.map. geo.admin.ch)

Table 6 Quality values of the first weighting function (Eq. 1) for candidate sites in site perimeter XN05

\begin{tabular}{llllllll}
\hline Site & Type & $\mathrm{G}$ & $\mathrm{N}$ & $\mathrm{E}$ & $\mathrm{C}$ & $\mathrm{D}$ & $\mathrm{P}$ \\
\hline XN05J & Residence & 1 & 1 & 1 & 1 & 1 & 11 \\
XN05O & Reservoir & 0.5 & 1 & 1 & 0.5 & 1 & 8.5 \\
XN05Q & Reservoir & 0.5 & 1 & 1 & 0.5 & 1 & 8.5 \\
XN05P & Reservoir & 0.5 & 1 & 0.5 & 0.5 & 1 & 7.5 \\
XN05H & Reservoir & 1 & 0.5 & 0.5 & 0 & 1 & 7 \\
XN05S & Bunker & 1 & 1 & 1 & 0.5 & 0.5 & 5.25 \\
XN05A & Lodge & 1 & 1 & 1 & 0 & 0.5 & 5 \\
XN05D & Residence & 1 & 0.5 & 1 & 1 & 0.5 & 4.5 \\
XN05E & Residence & 1 & 0.5 & 1 & 1 & 0.5 & 4.5 \\
XN05Z & Reservoir & 1 & 0.5 & 1 & 0.5 & 0.5 & 4.25 \\
XN05F & Reservoir & 1 & 0.5 & 1 & 0.5 & 0.5 & 4.25 \\
XN05C & Lodge & 0.5 & 1 & 1 & 0 & 0.5 & 3.5 \\
XN05B & Lodge & 0.5 & 0.5 & 1 & 0.5 & 0.5 & 3.25 \\
\hline
\end{tabular}


ranked fourth and fifth, they were not chosen for test measurements, because they located very close to the three top sites (XN05J, XN05S, and XN05Q).

Test measurements (step 4) were conducted for 8 days recording continuously. Data were subsequently analyzed in step 5 as described above. Figure 5 gives an example for the analysis of the background noise amplitude. The mean PSDPDF of all test measurements are shown together with the data from the two reference stations. Only sites XN05S and XN05J display mean seismic noise amplitude that is sufficient in both frequency ranges. Figure 6 presents a running spectrogram from test site XN05D. This site displays a strong seismic background noise, including narrow frequency noise and diurnal noise as well as transient noise events.

During the first test measurement period, only one local earthquake $(\mathrm{ML}=1.4)$ was recorded; arrival times could be picked at two sites (XN05J and XN05S) as shown in Fig. 7. During the second test measurement period, two local earthquakes were recorded (see Table 7). Results from the data analysis among more detailed information on installation and maintenance costs are evaluated using the second weighting function (step 6). The results are summarized in Tables 8 and 9. Our results from step 6 revealed that two sites (XN05S

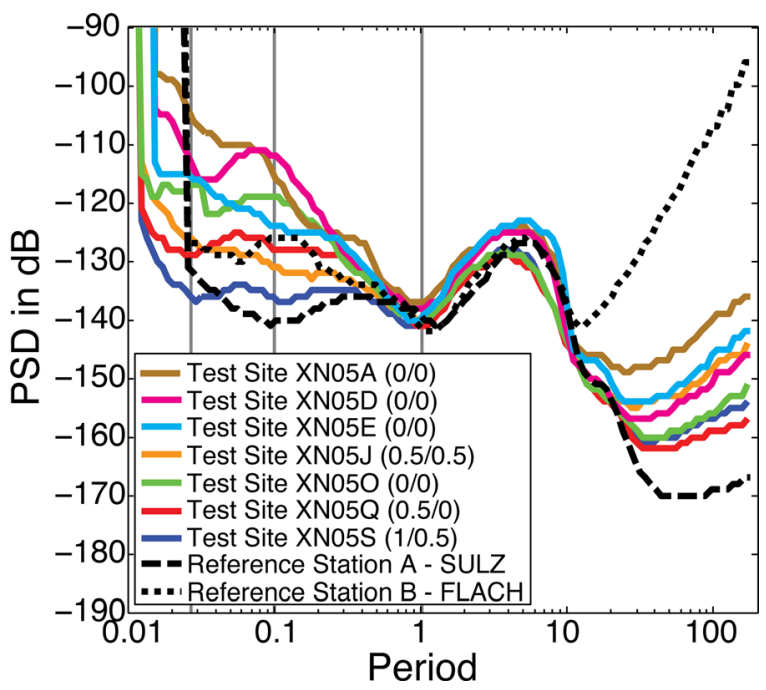

Fig. 5 Mean seismic background noise (NA) measured in site perimeter XN05. Shown are the mean functions of the PSDPDF for each test site as well as for the reference stations SULZ and FLACH. The noise is evaluated in the frequency ranges 1 to $10 \mathrm{~Hz}$ (NA1) and 10 to $40 \mathrm{~Hz}$ (NA2). The mean functions are used to define quality values as described in Table 2 . The resulting quality criteria for NA1 and NA2 are shown in brackets in the legend. Only sites XN05S and XN05J display a mean seismic noise amplitude that is acceptable in both frequency ranges and $\mathrm{XN} 05 \mathrm{~J})$ fulfilled the quality criteria (P2>10 and $\mathrm{N} 2>0.6$ ). Site XN05S displayed the lowest noise amplitude in the frequency range $1-10 \mathrm{~Hz}$ (Fig. 5 and Table 9). This site, however, lacked a telephone land line to allow for easy data communication. This was given at site XN05J but the seismic noise amplitude in the frequency range $1-10 \mathrm{~Hz}$ was higher due to a weak day time increase in noise (Fig. 5). On the other hand, installation costs for both sites were in agreement with the financial budget. Extra costs owing to the installation of a telephone land line to site XN05S were compensated by low installation costs. The location inside a discontinued military bunker did not require the construction of a seismometer vault. Because of the low noise level and acceptable installation costs, we decided to realize site XN05S. Unfortunately, while evaluating the different options to equip the site with data communication, the bunker was sold. The uncertainty in the future use made at this time the site unacceptable for us. As a consequence, the constant $\mathrm{A}$ in the second weighting function (Eq. 13) was set to zero, which yield $\mathrm{P} 2=0$ (Table 8 ).

Legal permission at site XN05J, which was now our preferred site, was uncertain and therefore we decided to continue with a twofold strategy. On the one hand, we continued negotiations with the land owner of XN05J, and on the other hand, we performed three additional test measurements at sites that were not considered in the first round (XN05A, XN05D, and XN05E). All these sites located more than $5 \mathrm{~km}$ from the center of the search perimeter. As a consequence, they were assigned a lower quality in the first weighing function (Table 6). The evaluation of the expected noise level and local geology, however, was promising.

We decided not to do additional test measurements at sites XN05P and XN05H although they ranked higher after step 3 (Table 6). Both sites were located at water reservoirs, and additional information revealed that a higher noise level has to be expected than originally assumed, because in both reservoirs machinery (pumps and air filters) were expected to increase noise levels in the $(10-40 \mathrm{~Hz})$ frequency range.

The additional test measurements were not successful, because the expected seismic background noise of all three stations had been underestimated.

At the end, permit negotiations were successful for site XN05J and the station called DAGMA was installed inside a newly build vault with approximately $1 \mathrm{~m}$ diameter. The vault locates within a meadow next to a 


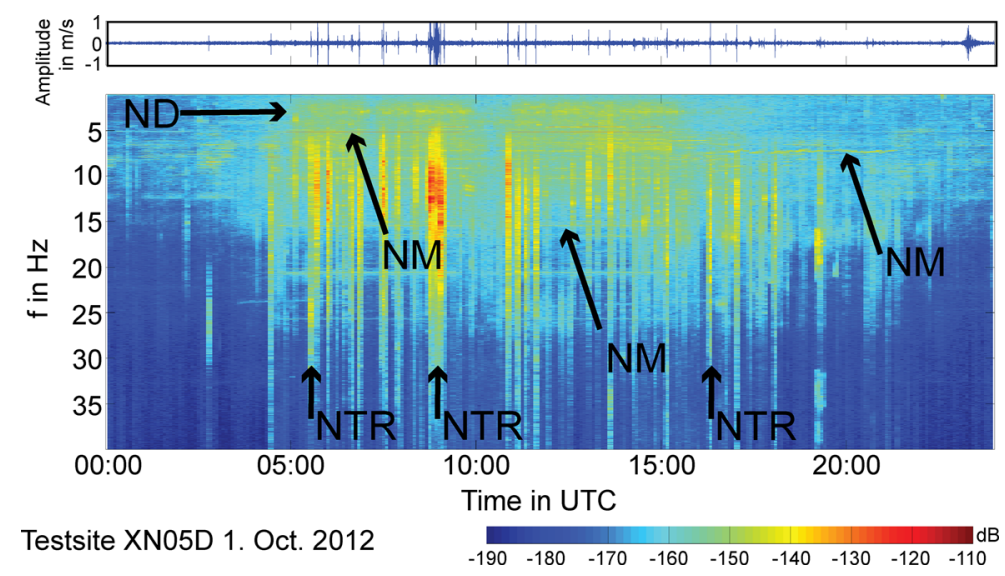

Fig. 6 Seismic background noise measured at candidate site XN05D. The spectrogram shown was recorded on 1 October 2012 and displays all different noise types analyzed in step 4: Narrow frequency noise (NM), transient noise signals (NT), and diurnal noise (ND). The waveform of the z-component is shown on top. The waveform amplitude is shown in the range -10 to

forest at a distance of approximately $40 \mathrm{~m}$ from a residential building. It sits directly on competent molasse rock (Helvetien, Obere Meeresmolasse). The closest street is located at about $50 \mathrm{~m}$ distance. DAGMA is equipped with a Nanometrics Trillium Compact seismometer and a Nanometrics Taurus data logger recording at a sampling frequency of $200 \mathrm{~Hz}$ since 11 April 2013.

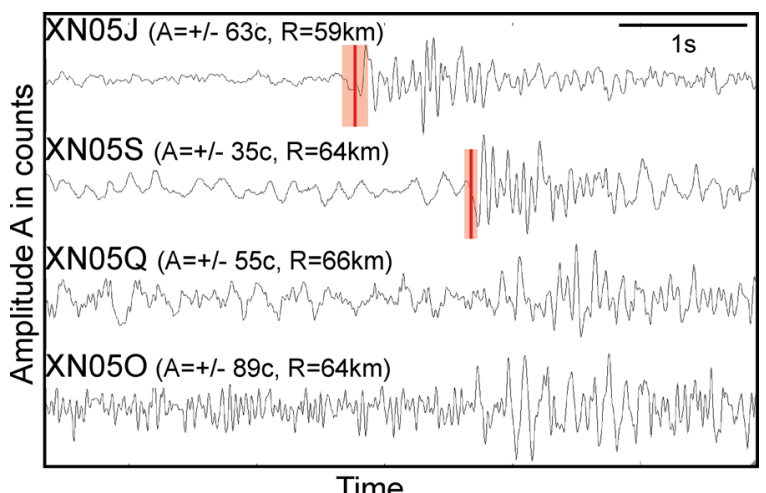

Fig. 7 Observed onset pick uncertainty at candidate sites of Site perimeter XN05. Data corresponds to a local earthquake that occurred on 30 August 2011 at 21:32:06 (UTC) with a source depth of $\mathrm{z}=8 \mathrm{~km}$ and a local magnitude of $\mathrm{M}=1.4$ (Details given in Table 7). Waveforms are normalized to the maximum amplitude with amplitude ranges given in brackets next to the station name. Red strokes mark the positions of phase onsets, bright red boxes mark the onset-time uncertainty, evaluated following the SED standard (Diehl et al. 2009). Only picks with a pick uncertainty $<0.2 \mathrm{~s}$ are shown. The observed onset-time uncertainty is translated to the observed pick quality criteria $O_{\mathrm{B}}$ following the definition given in Table 4
$10 \mathrm{~nm} / \mathrm{s}$. The noise amplitude is shown in dB relative to $1 \mathrm{~m} / \mathrm{s}$. In this example, the transient noise signals correspond to cars driving on a small street at about $50 \mathrm{~m}$ distance to the measurement. Diurnal noise is due to nearby settlements as seen in Fig. 4. The sources of the observed narrow frequency noise NM were not identified

After half a year operation, we find that DAGMA is performing in agreement with our test measurements at site XN05J. Noise characteristics (amplitude, occurrence of narrow frequency noise, diurnal variations, and transient events) of DAGMA correspond very well to those recorded during test measurements with the exception that mean noise amplitudes at frequencies $\mathrm{f}>20 \mathrm{~Hz}$ are slightly lower at DAGMA than during test measurements. This is to be expected because installation in a vault provides better shielding from highfrequency noise generated, e.g., by rain at the surface.

\section{Discussion}

During the installation of the Nagra network, 85 test measurements were performed. These test measurements allow us to review the seismic background noise inside a densely-populated area. Furthermore, we can compare the difference between the expected seismic

Table 7 Quality values for earthquake onset analysis (Eq. 7) in site perimeter XN05

\begin{tabular}{llllllll}
\hline Site & $\mathrm{c}$ & $\#$ & Distance & $\mathrm{O}_{\mathrm{B}}$ & $\mathrm{O}_{\mathrm{E}}$ & $\mathrm{G}$ & $\mathrm{O}$ \\
\hline XN05J & 1 & 1 & $59 \mathrm{~km}$ & 0.5 & 0 & - & 1 \\
XN05S & 1 & 1 & $64 \mathrm{~km}$ & 1 & 0 & - & 1 \\
XN05O & 0 & 1 & $66 \mathrm{~km}$ & 0 & 0 & 0.5 & 0.5 \\
XN05Q & 0 & 1 & $64 \mathrm{~km}$ & 0 & 0 & 0.5 & 1 \\
\hline
\end{tabular}


Table 8 Quality values for the second weighting function (Eq. 4) for candidate sites in site perimeter XN05

\begin{tabular}{lllllllc}
\hline Site & N2 & O & F & M & D & a & P2 \\
\hline XN05S & 0.71 & 1 & 1 & 1 & 0.5 & 0 & $0(11.83)$ \\
XN05J & 0.67 & 1 & 1 & 1 & 1 & 1 & 11.67 \\
XN05D & 0.25 & 1 & 0.5 & 1 & 0.5 & 1 & 8.5 \\
XN05A & 0.13 & 1 & 0.5 & 1 & 0.5 & 1 & 8.00 \\
XN05E & 0.29 & 1 & 1 & 1 & 0.5 & 1 & 9.67 \\
XN05Q & 0.54 & 0.5 & 1 & 1 & 1 & 1 & 7.17 \\
XN05O & 0.17 & 0.5 & 0.5 & 1 & 1 & 1 & 4.67 \\
\hline
\end{tabular}

background noise $\mathrm{N} 1$ and the measured seismic background noise N2.

For sites with test measurements, we find the following distribution:

- The expected seismic background noise N1 (step 3, prior to test measurements) was evaluated at 37 sites with a quality factor $\mathrm{N} 1=0.5$ and at 48 sites with a quality factor $\mathrm{N} 1=1$. The measured seismic background noise N2 (step 6) at the same sites reached values between $\mathrm{N} 2=0.1$ and $\mathrm{N} 2=1$.

- $\mathrm{N} 2<0.4$ was measured for $27 \%$ of the sites ranked with $\mathrm{N} 1=0.5$ and for $46 \%$ of the sites ranked with $\mathrm{N} 1=1.0$

- $\mathrm{N} 2>0.8$ were found for only $11 \%$ of the sites ranked with $\mathrm{N} 1=0.5$ and for $25 \%$ of the site ranked with $\mathrm{N} 1=1$. Hence, for sites ranked with $\mathrm{N} 1=1$, test measurements are more successful.

It follows that, on average, the expected seismic background noise was more or less confirmed by the test measurements. Nonetheless, we observe a broad range of measured noise quality values for criteria $\mathrm{N} 2$,

Table 9 Quality values of seismic background noise analysis (Eqs. 5 and 6) for candidate sites in site perimeter XN05.

\begin{tabular}{lllllll}
\hline Site & NA1 & NA2 & NM1 & NM2 & NT & N2 \\
\hline XN05S & 1 & 0.5 & 0.5 & 1 & 0.5 & 0.71 \\
XN05J & 0.5 & 0.5 & 0.5 & 1 & 1 & 0.67 \\
XN05D & 0 & 0 & 1 & 1 & 0 & 0.25 \\
XN05A & 0 & 0 & 0.5 & 0.5 & 0 & 0.13 \\
XN05E & 0 & 0 & 0.5 & 1 & 0.5 & 0.29 \\
XN05Q & 0.5 & 0 & 1 & 1 & 0.5 & 0.54 \\
XN05O & 0 & 0 & 0.5 & 1 & 0 & 0.17 \\
\hline
\end{tabular}

independent of the initially estimated quality value for noise criteria N1. Thus, occupationally very low background noise was measured at sites evaluated with a medium expected background noise only, and very poor noise conditions were found at sites where low background noise was expected. At these sites, the "gut feeling" of the seismologist failed. This result stresses the importance of test measurements for proper site selection.

In densely populated regions like Northern Switzerland noise sources are widespread. This poses a challenge on selecting proper sites using expert judgment only, even for a trained seismologist. We find that especially noise generated at larger distances is often underestimated during steps 1 and 2 (site pre-evaluation and site survey). Keeping a proper distance to all noise sources, as suggested by Trnkoczy et al. (2009), is often not possible, because of the high density of different noise sources. Moreover, site selection has always to find a balance between acceptable noise levels, existing infrastructure, and network geometry.

We find that the multi-step assessment scheme proposed in this paper proves very successful in assessing and weighting these different boundary conditions. Expert judgment is used in the first phase (steps 1-3), which is later quantified by the analysis of test measurements (steps 4-6). Two different weighting functions allow combining and weighting all necessary information in a more or less quantitative way. In these functions, different criteria allow to consider each information according to the defined goals of the final network by using different weighting factors.

We experienced that the multi-step assessment scheme is very helpful for documentation purposes. As site selection often is a process over longer time spans, we find that expert judgment became more biased with time. For example, the low noise amplitude and the remoteness of a certain site were reminded, but narrow frequency noise was forgotten. The assessment scheme was therefore a good reminder of all aspects that had to be taken into account. Especially, when returning to a perimeter, a long time after the test measurements (e.g., because the first site chosen could not be realized as in the example given), the assessment scheme allowed the seismologist to return quickly to the problem without neglecting important aspects. A proper documentation of the site search is moreover important for future network densifications, as it will prevent double work. Among documentation, we also find that the assessment scheme is very helpful in 
communicating to land owners, authorities, and the public. It breaks down the complex process of site evaluation to numbers, while at the same time demonstrating the complexity that needs to be taken into account. We find a high acceptance of the assessment scheme both in the discussion with official agencies or municipalities and in the discussion with private persons.

The assessment scheme presented was specifically designed for the Nagra network, as described above. It follows that our choice of weighing factors and equations may not be the right solution for every project, as different boundary conditions and targets apply. It is therefore important to note that our assessment scheme can be easily adapted to many different situations.

In both weighting functions (Eqs. 1 and 4), the three different components can be adjusted: the evaluated criteria, the weighting factors, and the definitions for the quality values.

In the first weighting function (Eq. 1), the quality criteria I (infrastructure) can easily be redefined by considering the following questions: Is an existing power line the only option for the station's power supply or are alternative sources such as batteries or solar panels possible? Is data stored locally or sent in real-time? Are data gaps acceptable or must they be avoided as, e.g., in sensitive monitoring environments (geothermal and mining)? Is the station endangered to vandalism or theft? Is it possible to build new secure installation housing (e.g., vaults) or is it necessary to use existing structures such as houses, bunkers, reservoirs, or abandoned mines?

Furthermore, quality criteria E (electricity) may be canceled for networks that are located in areas that do not provide any power line. For networks that do not have the finances to build new housing such as vaults, it might be useful to introduce a new quality criteria $\mathrm{H}$ "housing" that takes into account the availability of existing structures.

In addition, noise sources that should be considered depend strongly on the frequency range of the target signals. For example, exposure to wind plays an important role for signals below $1 \mathrm{~Hz}$, and all oscillating structures (trees, buildings, poles...) are a potential noise source.

With respect to the second weighting function (Eq. 4), it is often important to adjust the analysis of seismic background noise and of phase onsets, which will result in different quality factors. In the background noise analysis, the frequency range must be adjusted to the frequency content of the target signals. Also, the evaluation of phase onsets must be adjusted. As discussed, our approach is only possible for weak, local earthquakes, where the assumption that high-pick probability coincides with low pick uncertainty is reasonable. The latter is certainly not valid for events with more complex signal signatures, such as lowfrequency events or tremor.

As an example, we adopted the assessment scheme for the St. Gallen (SGT) network. The SGT network represents a temporary, small-scale network $(10-\mathrm{km}$ radius) of six stations, including one 205-m-deep borehole station (Fig. 2). The network has been installed and operated under a contract by Sankt Galler Stadtwerke to monitor seismicity potentially induced by a geothermal project (www.geothermie-stgallen.ch) in the city of St. Gallen, eastern Switzerland.

The following adjustments were incorporated in the assessment scheme:

First weighting function (see Table 1 for the Nagra settings):

- Adjusted quality values for quality criteria C (communication): Because the SGT network is located in a rather urban setting, mobile coverage is dense and no major disruptions are expected. We therefore chose a quality value of 1 for sites where UMTS was available.

- Adjusted the quality values for criteria distance D, because the smaller dimensions of the St. Gallen network required sites to be found within a $2 \mathrm{~km}$ radius (central stations SGT00 within $0.5 \mathrm{~km}$ and SGT01 within $1 \mathrm{~km}$ radius).

- Added additional quality criteria for housing H: Because of the temporary deployment the construction of new vaults was financially too expensive. Instead existing structures (mostly basements of water reservoirs) were used. Quality value 1=secure housing is available, quality value $0.5=$ housing is questionable, and quality value $0=$ no housing available.

The same weighting factors as for the Nagra network were used. The resulting first weighting function for the SGT network is accordingly:

$\mathrm{P} 1=(4 * \mathrm{~N} 1+4 * \mathrm{G}+2 *(\mathrm{E}+0.5 * \mathrm{C})) * \mathrm{H}^{*} \mathrm{D}$

The second weighting function used the same quality criteria and quality values as described for the Nagra network, because the SGT network aimed to monitor 
small, local events, as well. Only the weighting factors were adjusted, which resulted in the following weighting function: $\mathrm{P} 2=(6 \times \mathrm{N} 2+4 \times \mathrm{O}+2 \times \mathrm{F}+2 \times \mathrm{M}+$ D) $\times$ A. For the SGT-network, we use a higher weight for local seismic background noise, because we did not record any events from the target zone. For this reason, only local events originating from outside of the target zone could be considered.

The installation of the Nagra network using the multi-step assessment scheme took about 2 years. Delay was mostly due to difficulties in finding proper sites with acceptable noise levels, which resulted in large number of test measurements, lack of infrastructure (mainly data communication), and a complex legal permission process for some sites. The question arises whether the effort necessary to follow the assessment scheme and the long time period invested are worth it.

Figure 8 compares mean noise amplitudes of the newly installed Nagra stations and existing SDSNet stations in the same region. In the Jura region, mean noise amplitudes of the new Nagra stations are comparable to those of the SDSNet stations (Fig. 8a). The benefit of the multi-step assessment scheme is demonstrated in Fig. $8 \mathrm{~b}$ that shows stations located in the Molasse Basin. Despite unfavorable noise conditions and a poor geology, mean noise amplitudes in the frequency range $1-20 \mathrm{~Hz}$ are on average lower for the new Nagra stations.

Differences between the Jura-Black Forest perimeters and perimeters situated within the Molasse unit are also visible when comparing the total number of test measurements necessary to find an appropriate site. Whereas on average only four test measurements were conducted in the western perimeters in a hard rock and less populated environment, on average ten test measurements were necessary in the Molasse basin. We conclude that the multi-step assessment scheme is most beneficial in complicated settings that comprise both a less favorable geology as well as a dense spreading of noise sources.

\section{Conclusion}

We developed a multi-step assessment scheme for improved site selection during seismic network installation in densely-populated areas. Site selection is a complex
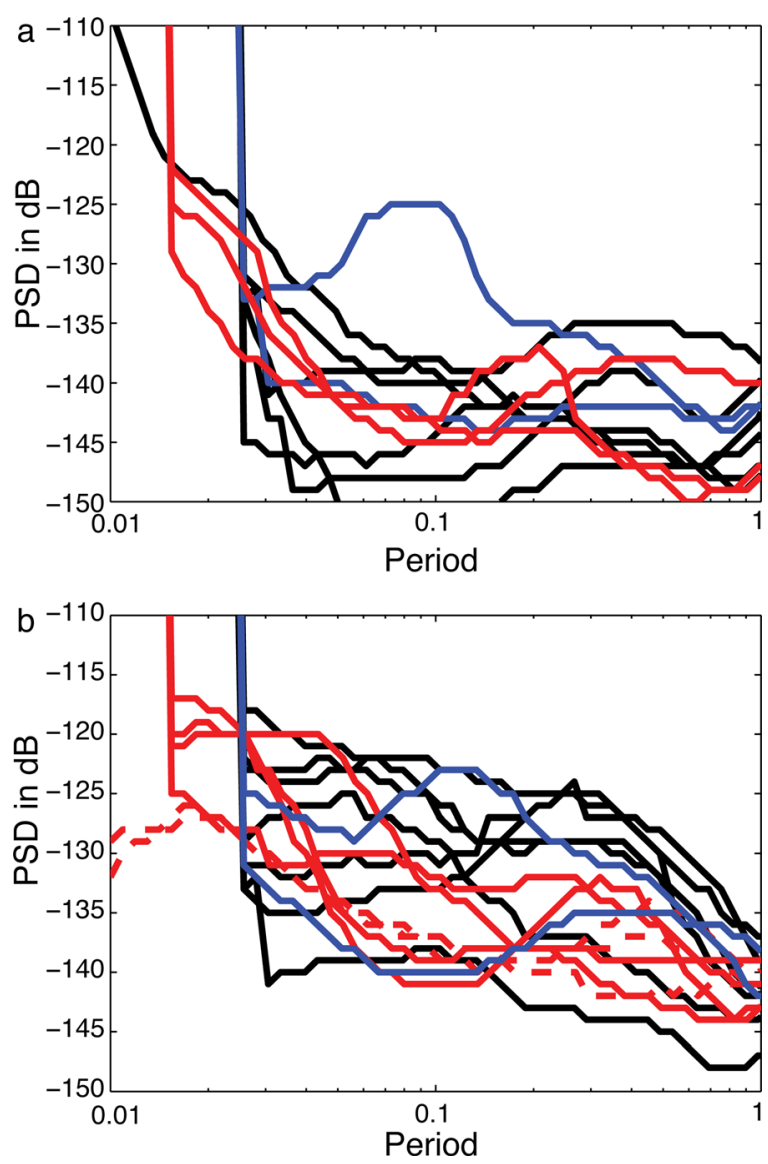

Fig. 8 Mean noise amplitude comparing new Nagra stations with other SDS-net stations. New Nagra surface stations are shown in red (solid line; surface station, dashed line; borehole station). Existing stations are shown in black; reference stations are shown in blue. Time period; 03 March to 01 April 2014. Neighboring stations in similar geological settings are shown: a Jura/Black forest and $\mathbf{b}$ Molasse basin. New Nagra stations in the Molasse Basin on average display a lower background noise level than older SDSnet stations despite regardless of their location in a densely populated area. We attribute this success to the multistep assessment scheme. (The displayed stations are a BALST, BERGE, BRANT, BOURR, GUT, KIZ, METMA, ROTHE, SULZ, SLE, TORNY and b ACB, BOBI, DAGMA, EMING, EMMET, FLACH, HAMIK, SLE, STEIN, STIEG, TRULL, WALHA, WEIN, WILA, ZUR)

process where different aspects (background noise, site effect, and financing) have to be taken into account, but is commonly performed by expert judgment and simple test measurements, only. A more sophisticated approach is needed, as more and more seismic networks are installed for real-time monitoring purposes in urban areas that exhibit a complex background noise field. In order to improve this process, we developed a step-wise approach that combines and weights all available and 
necessary information by the terms of two weighting functions and reference stations. Our approach improves the process for several reasons: First, it helps to objectively compare different potential and existing sites. Second, it is insured that the recording quality aimed for is reached. And finally, it is an easy way to document the decision process, because all relevant parameters are listed, quantified, and weighted.

We demonstrate the multi-step assessment scheme by applying it to two seismic network installations: (i) a regional network of ten stations (Nagra network) that densifies the existing Swiss Digital Seismic Network in northern Switzerland and (ii) a local seismic network (STG) to monitor a deep geothermal project close to the city of St. Galen, eastern Switzerland. Both networks are located in a densely populated region with an often unfavorable geology. By applying our multi-step assessment, we were able to find sites of equal or even better quality than existing stations in the region. We think that our multi-step assessment scheme is particularly applicable in projects with a limited financial budget where different options need to be weighted against each other (e.g., noise level versus existing infrastructure). Our application demonstrates that installing sensitive stations in densely populated areas is possible but requires significant efforts and time. Therefore, we recommend the application of our multi-step assessment scheme in regions with complex boundary conditions, such as high seismic background noise, unfavorable geology, and difficult infrastructure.

Data of the newly installed Nagra-network is open and can be accessed via the web site of the Swiss Seismological Service (http://arclink.ethz.ch).

\footnotetext{
Acknowledgments This work was financed by the Swiss National Cooperative for the Disposal of Radioactive Waste (Nagra) under contracts ETH 2-71504-10 and ETH 2-71506-10, and by the Swiss Federal Office of Energy (SFOE) and Sankt Gallener Stadtwerke (sgsw) through the project GeoBest. We like to thank our technical staff, especially Robert Tanner and Sacha Barman, for the technical support, our partners Michael Schnellmann and Herwig Müller from Nagra and Michael Sonderegger and Thomas Boch from sgsw for support and discussion, Falko Bethmann (now at: Geoenergie Suisse AG) for his support with the field work in the early phase of the project, Jochen Woessner for the PMC PDdistributions of the SDSnet reference stations, Valerio Poggi for site characterization analysis, John Clinton for valuable comments to the manuscript, and Joern Groos for providing his Matlab codes for spectrogram analsis. Reviews by Monika Sobiesak and an anonymous reviewer greatly improved our manuscript.
}

\section{References}

Aki K (1993) Local site effects on weak and strong motion. Tectonophysics 218:93-111

Aki K, Lee W (1976) Determination of three dimensional velocity anomalies under a seismic array using first $\mathrm{P}$ arrival times from local earthquakes. A homogeneous initial model. J Geophys Res 81:4381-4399

Baisch S, Fritschen R, Groos J, Kraft T, Plenefisch T, Plenkers K, Ritter J, Wassermann J (2012) Empfehlungen zur Überwachung induzierter Seismizität-Positionspapier des FKPE. Mitteilungen der Deutschen Geophysikalischen Gesellschaft V3:17-31

Bard, P. Y., (1999) Microtremor measurements: a tool for site effect estimation?, State-of-the-art paper, Second International Symposium on the Effects of Surface Geology on seismic motion, Yokohama, December 1-3, 1998, Irikura, Kudo, Okada \& Sasatani, (eds), Balkema 1999, 3, 1251-1279

Bard PY, Campillo M, Chavez-Garcia FJ, Sanchez-Sesma FJ (1988) Strong gound motion in Mexico City during the great Michoacan earthquake. Part B: A theoretical investigation of large- and small-scale amplification effects, Earthq. Spectra 4:609-633

Burjànek J, Gassner-Stamm G, Poggi V, Moore JR, Fäh D (2010) Ambient vibration analysis of an unstable mountain slope, Geophys. J Int 180:820-828

Carter JA, Barstow N, Pomeroy PW, Chael EP, Leahy PJ (1991) High-frequency seismic noise as a function of depth. Bull Seismol Soc Am 81(4):1101-1114

Diehl T, Kissling E, Husen S, Aldersons F (2009) Consistent phase picking for regional tomography models: Application to the greater Alpine region. Geophys J Int 176:542-554

Fischer T, Bachura M (2014) Detection capability of seismic network based on noise analysis and magnitude of completeness. J Seismol 18(1):137-150

Groos J, Ritter JRR (2009) Time domain classification and quantification of seismic noise in urban environment. Geophys J Int 179:1213-1231

Hardt M, Scherbaum F (1994) The design of optimum networks for aftershock recordings. Geophys J Int 117(3):716-726

Kijko A (1977) An algorithm for the optimum distribution of a regional seismic network. Pure Appl Geophys 115:999-1009

Kraft T, Mignan A, Giardini D (2013) Optimization of a largescale microseismic monitoring network in northern Switzerland. Geophys J Int 195(1):474 490

Mc Namara D.E, Boaz R I (2011) PQLX: A seismic data quality control system description, applications, and users manual. In: Open-File Report, vol 2010, 1292, U.S. Geological Survey

Mignan A, Werner MJ, Wiemer S, Chen C-C, Wu YM (2012) Bayesian estimation of the spatially varying completeness magnitude of earthquake catalogs. Bull Seismol Soc Am 101(3):1371-1385

Nakamura Y (1989) A method for dynamic characteristics estimations of subsurface using microtremors on the ground surface. QR RTRI 30:25-33

Nanjo KZ, Schorlemmer D, Woessner J, Wiemer S, Giardini D (2010) Earthquake detection capability of the Swiss Seismic Network. Geophys J Int 181:1713-1724

Nogoshi M, Igarashi T (1971) On the amplitude characteristics of microtremor (Part 2). J Seismol Soc Jpn 24:26-40 
Plenkers K, Ritter J, Schindler M (2013) Low signal-to-noise event detection based on waveform stacking and cross-correlation: Application to a stimulation experiment. J Seismol 17(1):27-49

Ritter JRR, Sudhaus H (2007) Characterization of small local noise sources with array seismology. Near Surface Geophysics 5(4):253-261

Schorlemmer D, Woessner J (2008) Probability of detecting an earthquake. Bull Seismol Soc Am 98:2103-2117

Souriau A, Woodhouse J (1985) A stategy for deploying a seismological network for global studies of earth structure. Bull Seismol Soc Am 75(4):1179-1193

Trnkoczy A, Bormann P, Hanka W, Holcomb L, Nibor R. L, Shinohara M, Shiobara H, Suyehiro K (2009) Site
Selection, Preparation and Installation of Seismic Stations. In: Bormann P (ed) New Manual of Seismological Observatory Practice (NMSOP-1), IASPEI, GFZ German Research Centre for Geosciences Potsdam

Young CJ, Chael EP, Zagar DA, Carter JA (1994) Variations in noise and signal levels in a pair of deep boreholes near Amarillo, Texas. Bull Seismol Soc Am 84(5):1593-1607

Young CJ, Chael EP, Withers MM, Aster RC (1996) A comparison of high-frequency $(>1 \mathrm{~Hz})$ surface and subsurface noise environment at three sites in the United States. Bull Seismol Soc Am 86(5):1516-1528

Zayats N, Steinberg D (2010) Optimal design of experiments when factors affect detection capability. Pak J Statist 26(1): 15-37 